\title{
What is the optimal target for a T2T approach in axial spondyloarthritis?
}

\author{
Joachim Sieper 지 , Denis Poddubnyy
}

An international expert group had formulated and recently updated a set of recommendations for treatment targets (treat to target-T2T) in axial spondyloarthritis (axSpA). ${ }^{1}$ According to these recommendations, the treatment target should be clinical remission/inactive disease defined as the absence of clinical and laboratory evidence of significant disease activity, which is currently best defined by reaching an Ankylosing Disease Activity Score (ASDAS) $<1.3$, termed ASDAS inactive disease. $^{2}$ In some mostly older studies, information is only available for another remission outcome, Assessment of Spondyloarthritis International Society (ASAS) partial remission. ${ }^{3}$ Only if it is not possible to achieve remission a low disease activity, which is defined as ASDAS <2.1, can be taken as an alternative target. Indeed, in observational axSpA cohorts, patients with an ASDAS $<1.3$ showed less spinal radiographic progression compared with patients with a higher ASDAS $^{4}$ and patients treated with tumour necrosis factor (TNF) blockers also showed less radiographic progression if the ASDAS was reduced to values $<1.3 .^{6}$ In addition, disease activity should be measured and treatment should be adjusted frequently (tight control) in order to reach an optimal control of disease activity.

On this background, a clinical trial investigating the concept of T2T in axSpA (1) has to define a treatment target to be reached, (2) has to define the frequency of the control measurements (tight control), (3) has to outline the treatment escalation in case the target is not reached and, finally, (4) an adequate control group has to be selected. To a further extent, it is desirable to demonstrate short-term and also long-term benefits of the T2T approach including inhibition of structural damage progression. Potential benefits should be carefully weighed against potential risks,

Department of Gastroenterology, Infectious Diseases and Rheumatology, Charité Universitätsmedizin Berlin, Berlin, Germany

Correspondence to Professor Joachim Sieper, Medical Department I, Rheumatology, Charite Universitatsmedizin Berlin, Berlin 12200, Germany; joachim.sieper@charite.de for example, risks associated with an intensified treatment in the T2T arm.

The study on T2T in axSpA published in this issue of the journal (TICOSPA) was therefore urgently needed and the results eagerly awaited for. ${ }^{7}$ For the treatment target, the authors chose low disease activity (ASDAS $<2.1$ ). Currently, it is not known if targeting low disease activity (that implies no treatment escalation if the ASDAS $<2.1$ but still $>1.3$ is reached) has disadvantages as compared with targeting inactive disease (ASDAS $<1.3$ ). In the opinion of the authors of this editorial, this question has to be explored in future trials using the T2T approach. The possibility to achieve ASDAS inactive disease is confirmed by data showing that in patients with axial spondyloarthritis-covering both patients with non-radiographic axSpA and radiographic (r) axSpA, also termed ankylosing spondylitis-who are selected based on shorter disease duration and the presence of objective signs of inflammation, such as an elevated C reactive protein (CRP) or active bony inflammation on MRI, inactive disease (ASDAS $<1.3$ ) can be reached consistently in between $45 \%$ and $50 \%$ of patients treated with a TNF blocker. ${ }^{8-11}$ Such a proportion of good responders is clearly lower in patients with axSpA not selected for such variables, ${ }^{12}$ as was done also in the TICOSPA study. Indeed, ASDAS inactive disease was reached in $26.4 \%$ of patients in the T2T arm while 59.7\% reached ASDAS low disease activity.

Once remission is achieved, the next step is to maintain this disease state. ${ }^{1}$ In a recent study, patients with axSpA with a disease duration $<5$ years were treated with the TNF blocker certolizumab pegol, and in those patients reaching remission (ASDAS $<1.3$ at weeks 32/36 and 48 ), the possibility of tapering treatment was investigated. ${ }^{11}$ Sustained low disease activity throughout week 96, which was chosen as the primary endpoint here, was reached by $84 \%(87 / 104)$ versus $73.0 \%$ $(77 / 105)$ versus $19 \%(20 / 104)$ of patients continuing the full dose of certolizumab, versus half of the dose versus placebo, respectively. The results were not very much lower if analysed for ASDAS inactive disease: $72 \% \quad(75 / 104), \quad 55 \% \quad(58 / 105)$ and $13 \%(14 / 104)$ of the second phase randomised patients, respectively, arguing that ASDAS inactive disease could also have been chosen as a primary endpoint without losing too many patients in such a study.

Escalation steps are quite limited in the treatment of axSpA and, as the first pre-biologic step, are restricted to non-steroidal anti-inflammatory drugs (NSAIDs). This is different, for example, to psoriatic arthritis. In another T2T study, the Tight Control in Psoriatic Arthritis (TICOPA) study, an escalation with a conventional synthetic diseasemodifying anti-rheumatic drug (DMARD) such as methotrexate and others was possible and was used. ${ }^{13}$ The potential of NSAIDs in the treatment as the first step is often neglected in axSpA ${ }^{14}$ and the ASAS NSAIDs intake index ${ }^{15}$ was indeed rather low in TICOSPA with a score between 30 and 40 at the time of enrolment and was not further increased in the T2T arm up to week 12, and went even further down during the study year in both arms. A question whether a combination of NSAID with a TNF-blocking agent is better than a TNF-blocking agent alone still awaits an answer in a prospective trial.

In a previous study comparing infliximab plus naproxen versus naproxen alone in early axSpA, we could show that ASDAS inactive disease was reached by $19.6 \%$ (and ASAS partial remission in $35.3 \%$ ) of patients treated with naproxen alone and in $51.4 \%$ of patients treated with a combination of naproxen plus infliximab.' Unfortunately, in this study an infliximab alone arm was not included. Thus, although NSAIDs and infliximab treatment both proved to be quite effective in this study, it remained unclear whether a combination therapy of a TNF blocker plus NSAID is better than TNFblocker therapy alone. Some information on this question will become available rather soon: in a currently ongoing study (CONSUL) in patients with AS, good responders to TNF-blocker treatment (golimumab) in the first 3 months are then randomised for 2 years for a treatment with the TNF blocker alone or TNF blocker plus celecoxib $400 \mathrm{mg}$ per day. ${ }^{16}$ Although the primary endpoint in this study will be radiographic progression, we will also get important information on whether a combination of TNF blocker with NSAIDs, compared with TNF blocker alone, has an effect on disease activity.

The first escalation step after NSAIDs treatment would be TNF blockers and it has also become possible in the last 
years to further switch to an interleukin (IL) -17 inhibitor $^{17}$ or even to start with an IL-17 inhibitor just after NSAIDs. In TICOSPA, only two patients were treated with the IL-17 inhibitor secukinumab after anti-TNF failure; thus, further studies are needed to address the optimal strategy after failure of the first-line DMARD. Most recently, the first Janus kinase (JAK) inhibitor upadacitinib (a JAK-1 inhibitor) has been approved for the indication of ankylosing spondylitis ${ }^{18}$ and another trial with this drug is ongoing for nr-axSpA, which will enlarge the treatment armamentarium for axSpA further. However, although in the current ASAS/EULAR treatment recommendations it is suggested to start with a TNF blocker as the first biologic ${ }^{17}$ - only because we have much longer experience with this class of drug not because they are more effective-we do not have data helping us to decide with which biologic or targeted synthetic DMARD to start and whether specific patients would be better candidates for one or the other DMARD. Similarly, we do not know the optimal sequence of switching between the biologic and whether a combination of biologics (or a biologic and a targeted synthetic DMARD) might be an option in patients who have failed one or two biologics. ${ }^{19}$ Furthermore, it has to be further explored if drugs with a direct inhibitory effect on CRP production (that could be the case for JAK inhibitors' mediated IL-6 inhibition) might be associated with a higher probability of ASDAS inactive disease/low disease activity achievement just because of CRP effect and not because of clinical efficacy. For an optimal T2T design, such information would be mandatory.

A normal treatment control group for a T2T study would be standard care, which was also the case in the current TICOSPA study. However, the European centres selected for the current study were-for both the T2T arm and for the standard care arm-interested or even specialised in SpA making it likely that the treating (standard care) physicians followed the ASAS/EULAR recommendations for the treatment of axSpA ${ }^{17}$ which are similar to the one applied in the T2T arm. Furthermore, patients and investigators were not blinded for the treatment arms, which might have induced a larger placebo response in the $\mathrm{T} 2 \mathrm{~T}$ arm.

However, as an advantage, such a study design permits to apply the results immediately to daily clinical practice because every physician can use such a T2T approach for their patients. The results in the T2T arm were indeed numerically (not reaching statistical significance) better for many variables suggesting that using a pre-specified strategy based on treatment intensification until achieving a target, in this case an ASDAS of $<2.1$, might be superior to standard care. For example, an improvement of the ASAS health index ${ }^{20}$ by $30 \%$ (the primary endpoint) was reached by $47.3 \%$ in the $\mathrm{T} 2 \mathrm{~T}$ arm versus $36.1 \%$ in the control arm and low disease activity was reached in 59.7\% versus 50.8\%, respectively. The results would have even been probably more in favour of the T2T arm if rheumatologists not specialised in SpA had been selected for the study. Interestingly, also a cost-utility analysis favoured the T2T arm. In the TICOSPA study, the overall number of adverse events was with 33 versus 22 higher in the T2T arm as compared with the usual care arm, mostly driven by allergic reactions, a result which this should be part of the risk-benefit assessment.

The results of the TICOSPA study might even be of more relevance with regard to the axSpA treatment recommendations by ACR/SAA/SPARTAN ${ }^{21}$ because disease activity scores are not part of these recommendations and active disease is defined by the severity of patient's symptoms without further specification, thus being more similar to the control arm in TICOSPA.

However, if a T2T study in axSpA wants to address the questions whether remission can be reached, how remission can be reached and whether reaching remission (and maintaining remission) by a T2T approach is superior to usual care, and to achievement of low disease activity instead of remission, on the long term, a prospective interventional study (rather studies, since it would not be possible to address all questions in just one study) would be necessary. Especially for the treatment escalation step after NSAIDs failure, more information should be available from (yet to be planned) trials about the selection of the first biologic according to the patients' characteristics, about the switch of biologics and about the potential of combinations of drugs. At the moment, we only have very limited information about specific treatments on the group level and even this only by indirect comparisons.

\section{Handling editor Josef S Smolen}

Contributors Both authors contributed to the design and to the writing of this article (editorial).
Funding The authors have not declared a specific grant for this research from any funding agency in the public, commercial or not-for-profit sectors.

Competing interests JS: consulting fees from AbbVie; UCB speaker fees from AbbVie, Janssen, Novartis and Merck. DP: research support from AbbVie, Eli Lilly, MSD, Novartis and Pfizer; consulting fees from AbbVie, Biocad, Gilead, GlaxoSmithKline, Eli Lilly, MSD, Novartis, Pfizer and Samsung Bioepis; UCB speaker fees from AbbVie, Bristol-Myers Squibb, Eli Lilly, MSD, Novartis, Pfizer and UCB.

Patient and public involvement Patients and/or the public were not involved in the design, or conduct, or reporting, or dissemination plans of this research.

Patient consent for publication Not required.

Provenance and peer review Commissioned; externally peer reviewed.

\section{(0) OPEN ACCESS}

Open access This is an open access article distributed in accordance with the Creative Commons Attribution Non Commercial (CC BY-NC 4.0) license, which permits others to distribute, remix, adapt, build upon this work non-commercially, and license their derivative works on different terms, provided the original work is properly cited, appropriate credit is given, any changes made indicated, and the use is non-commercial. See: http:// creativecommons.org/licenses/by-nc/4.0/.

(C) Author(s) (or their employer(s)) 2021. Re-use permitted under CC BY-NC. No commercial re-use. See rights and permissions. Published by BMJ.

\section{Check for updates}

To cite Sieper J, Poddubnyy D. Ann Rheum Dis 2021;80:1367-1369.

Received 1 June 2021

Accepted 9 June 2021

Published Online First 18 June 2021

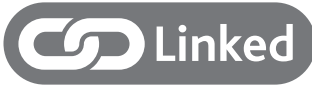

http://dx.doi.org/10.1136/annrheumdis-2020219585

Ann Rheum Dis 2021:80:1367-1369.

doi:10.1136/annrheumdis-2021-220603

\section{ORCID iDs}

Joachim Sieper http://orcid.org/0000-0003-0285-9890 Denis Poddubnyy http://orcid.org/0000-0002-45376015

\section{REFERENCES}

1 Smolen JS, Schöls M, Braun J, et al. Treating axial spondyloarthritis and peripheral spondyloarthritis, especially psoriatic arthritis, to target: 2017 update of recommendations by an international task force. Ann Rheum Dis 2018;77:3-17.

2 Machado PM, Landewe R, Heijde DV, Assessment of SpondyloArthritis international Society (ASAS). Ankylosing Spondylitis Disease Activity Score (ASDAS): 2018 update of the nomenclature for disease activity states. Ann Rheum Dis 2018;77:1539-40.

3 Anderson JJ, Baron G, van der Heijde D, et al. Ankylosing spondylitis assessment group preliminary definition of short-term improvement in ankylosing spondylitis. Arthritis Rheum 2001;44:1876-86. 
4 Ramiro S, van der Heijde D, van Tubergen A, et al. Higher disease activity leads to more structural damage in the spine in ankylosing spondylitis: 12-year longitudinal data from the OASIS cohort. Ann Rheum Dis 2014;73:1455-61.

5 Poddubnyy D, Protopopov M, Haibel H, et al. High disease activity according to the Ankylosing Spondylitis Disease Activity Score is associated with accelerated radiographic spinal progression in patients with early axial spondyloarthritis: results from the GErman SPondyloarthritis Inception Cohort. Ann Rheum Dis 2016;75:2114-8.

6 Molnar C, Scherer A, Baraliakos X, et al. TNF blockers inhibit spinal radiographic progression in ankylosing spondylitis by reducing disease activity: results from the Swiss Clinical Quality Management cohort. Ann Rheum Dis 2018;77:63-9.

7 Molto A, López-Medina C, Van den Bosch FE, et al. Efficacy of a tight-control and treat-to-target strategy in axial spondyloarthritis: results of the open-label, pragmatic, cluster-randomised TICOSPA trial. Ann Rheum Dis 2021;80:1436-44.

8 Song I-H, Hermann K, Haibel H, et al. Effects of etanercept versus sulfasalazine in early axial spondyloarthritis on active inflammatory lesions as detected by whole-body MRI (ESTHER): a 48week randomised controlled trial. Ann Rheum Dis 2011;70:590-6.

9 Sieper J, Lenaerts J, Wollenhaupt J, et al. Efficacy and safety of infliximab plus naproxen versus naproxen alone in patients with early, active axial spondyloarthritis: results from the double-blind, placebo-controlled INFAST study, part 1. Ann Rheum Dis 2014;73:101-7.

10 Landewé $\mathrm{R}$, Sieper J, Mease $\mathrm{P}$, et al. Efficacy and safety of continuing versus withdrawing adalimumab therapy in maintaining remission in patients with non-radiographic axial spondyloarthritis (ABILITY-3): a multicentre, randomised, double-blind study. Lancet 2018;392:134-44.

11 Landewé RB, van der Heijde D, Dougados $M$, et al. Maintenance of clinical remission in early axial spondyloarthritis following certolizumab pegol dose reduction. Ann Rheum Dis 2020;79:920-8.

12 van der Heijde D, Dijkmans B, Geusens P, et al. Efficacy and safety of infliximab in patients with ankylosing spondylitis: results of a randomized, placebo-controlled trial (ASSERT). Arthritis Rheum 2005; 52:582-91.

13 Coates LC, Moverley AR, McParland L, et al. Effect of tight control of inflammation in early psoriatic arthritis (TICOPA): a UK multicentre, open-label, randomised controlled trial. Lancet 2015;386:2489-98.

14 Song IH, Poddubnyy DA, Rudwaleit M, et al. Benefits and risks of ankylosing spondylitis treatment with nonsteroidal antiinflammatory drugs. Arthritis Rheum 2008;58:929-38.

15 Dougados M, Simon P, Braun J, et al. ASAS recommendations for collecting, analysing and reporting NSAID intake in clinical trials/epidemiological studies in axial spondyloarthritis. Ann Rheum Dis 2011;70:249-51.

16 Proft F, Muche B, Listing J, et al. Study protocol: COmparison of the effect of treatment with
Nonsteroidal anti-inflammatory drugs added to antitumour necrosis factor a therapy versus anti-tumour necrosis factor a therapy alone on progression of StrUctural damage in the spine over two years in patients with ankyLosing spondylitis (CONSUL) - an open-label randomized controlled multicenter trial. BMJ Open 2017;7:e014591.

17 van der Heijde D, Ramiro S, Landewé R, et al. 2016 update of the ASAS-EULAR management recommendations for axial spondyloarthritis. Ann Rheum Dis 2017;76:978-91.

18 van der Heijde D, Song I-H, Pangan AL, et al. Efficacy and safety of upadacitinib in patients with active ankylosing spondylitis (SELECT-AXIS 1): a multicentre, randomised, double-blind, placebo-controlled, phase 2/3 trial. Lancet 2019;394:2108-17.

19 Poddubnyy D, Sieper J. What is the best treatment target in axial spondyloarthritis: tumour necrosis factor $\alpha$, interleukin 17, or both? Rheumatology 2018;57:1145-50.

20 Kiltz U, van der Heijde D, Boonen A, et al. Development of a health index in patients with ankylosing spondylitis (ASAS HI): final result of a global initiative based on the ICF guided by ASAS. Ann Rheum Dis 2015;74:830-5.

21 Ward MM, Deodhar A, Gensler LS, et al. 2019 update of the American College of Rheumatology/ Spondylitis Association of America/Spondyloarthritis Research and Treatment Network recommendations for the treatment of ankylosing spondylitis and nonradiographic axial spondyloarthritis. Arthritis Care Res 2019;71:1285-99. 